\title{
Medicinos darbuotojų Lietuvoje ir JAV pasitenkinimo darbu, empatijos ir psichikos sveikatos sąsajos
}

\author{
Dovilè MILIŠAUSKAITÉ ${ }^{1}$ \\ Mykolo Romerio universitetas
}

\begin{abstract}
Santrauka. Tiek empatija, tiek ir psichikos sveikata medicinos darbuotojams yra ypatingai svarbios tam, kad jis būtų patenkintas darbu ir galètų efektyviai dirbti. Šiuo tyrimu siekiama palyginti Lietuvoje ir Jungtinėse Amerikos Valstijose (JAV) dirbančiu medicinos darbuotojų empatijos, psichikos sveikatos ir pasitenkinimo darbu sąsajas. Metodika. Tyrime dalyvavo po 50 abiejų šalių medicinos darbuotojų, kurie pilde Džefersono empatijos skalę, Pasitenkinimo darbu klausimyną ir Psichikos sveikatos klausimyną. Rezultatai. Rezultatai atskleide, kad Lietuvos imtyje rastos sąsajos tarp empatijos, psichikos sveikatos ir pasitenkinimo darbu, tačiau medicinos darbuotojų JAV imtyje ryšiai buvo rasti tik tarp psichikos sveikatos ir pasitenkinimo darbu. Taip pat rezultatai parodė, kad Lietuvos imtyje empatija ir psichikos sveikata nèra svarbūs veiksniai prognozuojant pasitenkinimą darbu, kuomet medicinos darbuotojų JAV psichikos sveikata yra svarbus veiksnys prognozuojant pasitenkinimą darbu. Išvados. Remiantis gautais rezultatais matyti, kad egzistuoja skirtumai tarp Lietuvos ir JAV medicinos darbuotojų psichologinių charakteristikų.
\end{abstract}

Pagrindiniai žodžiai. empatija, psichikos sveikata, pasitenkinimas darbu, tarpkultūriniai skirtumai, medicinos darbuotojai.

\section{Ivadas}

Tiek empatija, tiek ir psichikos sveikata medicinos darbuotojams yra ypatingai svarbios tam, kad jie galètų efektyviai atlikti savo darbą (Di Blasi, Harkness, Ernst, Georgiou, \& Kleijnen, 2001; Cottini \& Lucifora, 2013). Medicinos sektoriuje dirbantiems žmonėms empatija yra reikšminga, nes ji padeda pažvelgti i pacientą iš jo perspektyvos, leidžia suprasti jo jausmus bei i juos atsakyti (Mercer \& Reynolds, 2002). Tai užtikrina pacientogydytojo kontaktą bei pasitikèjimą gydytoju (Rogers, 1957). Empatija svarbi medikui ne vien tik dèl teigiamo kontakto su pacientu. Empatija yra įvardijama kaip vienas iš profesionalumo medicinos srityje elementų (Arnold, 2002), kadangi gydytojo empatija yra teigiamai susijusi su ligos prognozès tikslumu (Dubnicki, 1977).

Medikams darbo praktikoje svarbų vaidmenį vaidina ne tik jaučiama empatija pacientui, bet ir jų pačių psichikos sveikata. Medicinos darbuotojai dažniau nei kitokio pobūdžio darbą dirbantys specialistai yra linkę turèti psichikos sveikatos sunkumų (Mori \& Kageyama, 1995, cit. pagal Suzuki et al., 2004), nes neretai tenka dirbti naktines pamainas, viršvalandžius, darbo grafikas būna dažnai nereguliarus (Suzuki et al., 2004). Miego trūkumas, sunkumai darbe sukelia stresą, o stresas yra vienas iš faktorių, susijusių su psichikos sveikata (Lauder, Kroll, \& Jones, 2007). Prasta psichikos sveikata gali neigiamai paveikti medicinos darbuotojo darbo kokybę bei pasitenkinimą darbu (Fiabane, Giorgi, Sguazzin, \& Argentero, 2013; Thommasen, Lavanchy, Connelly, Berkowitz, \& Grzybowski, 2001; Williams et al., 2000).

Išsiskiriantys duomenys Lietuvos ir JAV imtyse skatina analizuoti ryšius tarp empatijos, psichikos sveikatos ir pasitenkinimo darbu. Lyginant JAV ir Lietuvos studentų imtis paaiškejjo, kad JAV studentų psichikos sveikata yra geresnè nei Lietuvos studentų (Kononovas \& Dallas, 2009). Tačiau kalbant apie medicinos darbuotojus kyla daug abejonių, ar galima remtis tokiais rezultatais, nes JAV medicinos darbuotojų darbo krūvis yra didesnis nei Lietuvos medikų (World Health Organization, 2014). Pavyzdžiui, 2010 metais vienam JAV bendrosios praktikos gydytojui vidutiniškai atiteko 417 gyventojai, kai Lietuvos gydytojui - 278 gyventojai (World Health Organization, 2014). Atlikti tyrimai rodo, kad JAV medikai yra labai nusivylę savo darbu dèl didelio dokumentacijos kiekio bei ịvairių valstybinių reglamentų (Onieal, 2008). Didelis darbo krūvis gali neigiamai paveikti medicinos darbuotojo psichikos sveikatą (Altaf \& Awan, 2011). Lietuvos ir JAV medicinos darbuotojų palyginimas gali atskleisti reikšmingų skirtumų tarp dviejų demografiškai ir kultūriškai skirtingų šalių.

Medicinos darbuotojų empatija retai yra tyrinejjama tarpkultūriniame kontekste. Taip pat nepavyksta rasti Lietuvos medicinos darbuotojų ir kitų šalių medikų psichologinių charakteristikų palyginimo. Skirtingų kultūrų medicinos specialistų palyginimas gali būti naudingas ugdant medikus bei sudarant ịvairias mokymų programas. Iki šiol atlikti empatijos, psichikos sveikatos ir pasitenkinimo darbu sąsajų tyrimai atskleidžia prieštaringus rezultatus. Pavyzdžiui, dar vis neaišku, ar empatija daro teigiamą poveiki medicinos darbuotojo psichikos sveikatai, ar neigiamą. Vieni duomenys atskleidžia, kad empatija yra neigiamai susijusi su perdegimo sindromu, todèl daroma prielaida, kad dažnas empatijos pojūtis palaiko psichiškai sveikos asmenybės funkcionavimą arba kad psichiškai 
sveika asmenybė yra labiau empatiška (Paro et al., 2014). Tačiau kiti rezultatai nurodo priešingą ryši tarp empatijos ir psichikos sveikatos (Perry, 2003; Larson \& Yao, 2009). Viena iš priežasčių, dèl kurios specialistai, dirbantys su traumas patyrusiais pacientais, turi didesnę riziką antrą kartą išgyventi savo asmenines traumas, yra empatija (Perry, 2003). Keliama prielaida, kad empatiškas gydytojas gali tapti pažeidžiamas bei perimti kai kuriuos su trauma susijusius jausmus, pvz., skausmą (Perry, 2003). Taip pat dèl neigiamų emocijų empatizavimo ar pastangu kontroliuoti ryšị tarp savęs ir paciento gydytojams dideja perdegimo sindromo, o kartu ir suprastejjusios psichikos sveikatos, rizika (Larson \& Yao, 2009). Dẻl skirtingų rezultatų ir tyrinèjimų tarpkultūriniame kontekste trūkumo yra reikalingi tolimesni tyrimai.

Šiuo darbu yra siekiama palyginti Lietuvoje ir JAV dirbančių medicinos darbuotojų psichologines būsenas: pasitenkinimą darbu, psichikos sveikatą, empatiją bei jų tarpusavio sąsajas.

\section{Metodika}

\subsection{Tyrimo dalyviai}

Tyrime dalyvavo 100 privataus sektoriaus medicinos darbuotojų (50 - dirbančių Lietuvoje; 50 - dirbančių JAV). Iš jų 29 proc. buvo vyrai (Lietuvos imtyje - 22 proc.; JAV - 36 proc.) ir 71 proc. moterys (Lietuvos imtyje - 78 proc.; JAV- 64 proc.). Medicinos darbuotojų Lietuvoje amžiaus vidurkis $M=37,8, S D=11,94$. JAV medicinos darbuotojų imtyje amžiaus vidurkis $M=38,3, S D=12,94$. Daugiausia tyrime dalyvavo slaugytojo $(\mathrm{n}=30)$ arba odontologo $(\mathrm{n}=16)$ profesiją igyjusių specialistų. Tyrime taip pat dalyvavo oftalmologų, pediatrijos, flebotomijos reabilitologijos ir kt. sričių specialistai.

\subsection{Tyrime naudoti instrumentai}

Pasitenkinimas darbu buvo matuojamas P. E. Spector (1985) Pasitenkinimo darbu klausimynu (angl. Job Satisfaction Survey) (lietuviškosios ir angliškosios versijų Kronbacho alfa =0,91). Taikant MTMM (angl. multitraitmultimethod) ir faktorinę analizes bei skaičiuojant subskalių tarpusavio koreliacijas buvo patvirtintas skalès diskriminantinis bei konvergentinis validumai (Spector, 1985). I lietuvių iš anglų kalbos klausimyną vertė E. Rosenaitè ir N. Norvilè. Medicinos darbuotojų empatija matuota taikant Džefersono empatijos skalę (angl. Jefferson Scale of Empathy), kuri sukurta gydytojams ir kitiems sveikatos priežiūros specialistams (Hojat \& Mangione, 2001). Empatijos skalès lietuviškosios versijos Kronbacho alfa $=0,79$, o angliškosios - Kronbacho alfa $=0,74$. Taikant kriterijaus validumo metodą buvo nustatyta reikšminga vidutinio dydžio koreliacija $(\mathrm{r}=0,45 ; \mathrm{p}<0,01)$ tarp Tarpasmeninio reaktyvumo indekso skalès (angl. Interpersonal Reactivity Index) ir Džefersono gydytojų empatijos skalès (angl. Jefferson Scale of Physician Empathy) (Hojat, Mangione, Kane, Gonnella, 2005). Ši klausimyną iš anglų kalbos i lietuvių išvertè V. Stanionytė. Psichikos sveikata buvo matuota pasitelkiant Psichikos sveikatos klausimyną (angl. Mental Health Inventory) iš Medicininių baigčių studijos (angl. Medical Outcomes Study) (lietuviškosios versijos Kronbacho alfa $=0,96$, o angliškosios - Kronbacho alfa $=0,95$ ). Tikrinant skalès diskriminantinị validumą buvo atskleista, kad visi teiginiai viršijo 0,15 diskriminantinio validumo kriterijų, tai pagrindè dviejų psichikos sveikatos dimensijų - psichologinės gerovès ir psichologinio distreso - naudojimą skalëje (Veit, Ware, 1983). Klausimynas iš anglų i lietuvių kalbą buvo išverstas taikant dviejų nepriklausomų vertimų metodą.

\subsection{Tyrimo eiga}

Tyrimas buvo atliktas 4 skirtingose privačiose medicinos įstaigose Vilniuje bei 1 privačioje medicinos įstaigoje JAV (Naujojo Džersio valstijoje). Visose įstaigose iš atsakingų asmenų buvo gauti raštiški sutikimai atlikti tyrimą. Be konkrečių įstaigų medicinos darbuotojų klausimynai pagal patogiosios imties sudarymo būdą buvo išdalinti pavieniams medicinos darbuotojams, dirbantiems kitose privačiose medicinos įstaigose.

Gavus užpildytus klausimynus buvo atrinkti tie, kurie buvo užpildyti iki pabaigos. Gauti duomenys buvo apdorojami SPSS 21.0 paketu. Tyrime analizuojamoms pasitenkinimo darbu, empatijos ir psichikos sveikatos sąsajoms apskaičiuoti buvo naudojamas koreliacinis metodas ir daugialypè tiesinè regresinè analizè. Koreliacijų tarp kintamuju skirtumui paskaičiuoti buvo taikomas Fisher transformacijos metodas.

\section{Rezultatai}

Atlikta duomenų analizè atskleidè, kad egzistuoja sąsajos tarp pasitenkinimo darbu ir empatijos $(r=0,32 ; p<0,05)$, empatijos ir psichikos sveikatos $(r=0,32 ; p<0,05)$ ir psichikos sveikatos ir pasitenkinimo darbu $(r=0,35 ; p<$ $0,05)$ Lietuvos medicinos darbuotojų imtyje. JAV medicinos darbuotojų imtyje sąsajos buvo rastos tarp pasitenkinimo darbu ir psichikos sveikatos $(r=0,56 ; p<0,01)$. Kadangi pasitenkinimas darbu ir psichikos sveikata 
teigiamai koreliavo abiejose imtyse, buvo tikrinamas sąsajų skirtumo reikšmingumas taikant Firsher transformaciją. Rezultatai atskleidè, kad tarp šių koreliacijų reikšmingo skirtumo nėra $(z=1,25 p=0,211 ;$;). Statistiškai reikšmingu koreliacijų tarp empatijos ir pasitenkinimo darbu ir empatijos ir psichikos sveikatos JAV imtyje nebuvo rasta.

Kintamujų vidurkių palyginimu nustatyti buvo remiamasi neparametrinès statistikos Mann-Whitney U testu. Skaičiavimai parodè, kad reikšmingų skirtumų tarp pasitenkinimo darbu $(U=1130,000 ; p=0,408)$, empatijos $(U=$ $1004,000 ; p=0,122)$ ir psichikos sveikatos $(U=1160,000 ; p=0,649)$ lygio Lietuvos ir JAV medicinos darbuotojų imtyse nebuvo.

Siekiant ịvertinti empatijos ir psichikos sveikatos prognostinę reikšmę pasitenkinimui darbu, buvo atlikta daugialype tiesinè regresijos analizè. Iš gautų rezultatų yra matyti, kad JAV imtyje koreguotasis $\mathrm{R}^{2}$ yra pakankamai aukštas ir modelis paaiškina apie 28 proc. duomenų sklaidos. Modelio reikšmingumo lygmuo (p) taip pat rodo, kad galima daryti interpretacijas apie medicinos darbuotojų JAV pasitenkinimą darbu. Lietuvos imtyje koreguotasis $\mathrm{R}^{2}$ yra nepakankamas, kadangi jis paaiškina tik 13 proc. gautų duomenų sklaidos, todèl šiame modelyje prognozės negalimos. Yra matyti, kad JAV imtyje svarbesnis veiksnys prognozuojant pasitenkinimą darbu yra psichikos sveikata nei empatija. Daugialypès tiesinès regresijos statistika abiejose imtyse yra pateikta 1 lenteleje.

1 lentelè. Medicinos darbuotojų Lietuvoje ir JAV pasitenkinimo darbu ir empatijos bei psichikos sveikatos daugialypès tiesinès regresijos statistika

\begin{tabular}{llccccc}
\hline Imtis & Kintamasis & $\boldsymbol{\beta}$ & $\mathbf{p}$ & Koreguotasis R $^{2}$ & Durbin-Watson & Modelio reikšmingumo lygmuo (p) \\
\hline \multirow{2}{*}{ Lietuvos medikai } & Empatija & 0,220 & 0,128 & 0,129 & \multirow{2}{*}{0,560} & 0,015 \\
\multirow{2}{*}{ JAV medikai } & Psichikos sveikata & 0,273 & 0,061 & & 2,190 & 0,000 \\
& Empatija & 0,166 & 0,189 & 0,279 & 0,000 & \\
\hline
\end{tabular}

\section{Rezultatų aptarimas}

Šiuo tyrimu buvo siekiama analizuoti pasitenkinimo darbu, empatijos ir psichikos sveikatos sąsajas Lietuvos ir JAV privačiuose medicinos sektoriuose. Rezultatai atskleidè, kad tarp šių trijų kintamųjų egzistuoja tarpusavio sąsajos Lietuvos medicinos darbuotojų imtyje. Šie duomenys paremia anksčiau padarytas išvadas, kad empatija yra neigiamai susijusi su perdegimo sindromu, o tai reiškia, kad labiau empatiškas individas yra geresnès psichikos sveikatos (Paro et al., 2014). Taip pat yra duomenų, kurie nurodo, kad medikas, matydamas, kaip padeda pacientams sveikti, jaučiasi geriau (Radley \& Figley, 2007). Tai gali patvirtinti ir gautas teigiamas empatijos ir pasitenkinimo darbu sąsajas, kadangi matydamas pozityvius pokyčius paciento sveikatoje medicinos darbuotojas gali pastebėti teigiamus savo darbo rezultatus ir dèl to jaustis labiau patenkintas savo darbu. Rastos psichikos sveikatos ir pasitenkinimo darbu sąsajos patvirtina ir kitų tyrèjų gautus rezultatus, nurodančius, kad gydytojų patiriama depresija ir perdegimo sindromas yra susijęs su nepasitenkinimu esama situacija darbe ir noru pasitraukti iš darbo (Thommasen et al., 2001). Taip pat yra teigiama, kad sveikesnis ir laimingesnis medicinos darbuotojas gali geriau pasirūpinti savo pacientais (Burks \& Kobus, 2012), o produktyvumas ir geri rezultatai darbe didina pasitenkinimą darbu (Bockerman \& Ilmakunnas, 2012).

Analizuojant šių reiškinių sąsajas JAV medicinos darbuotojų imtyje paaiškèjo, kad empatija nèra susijusi nei su pasitenkinimu darbu, nei su psichikos sveikata. Tai gali reikšti, kad medikams JAV yra svarbūs kiti veiksniai, kurie siejasi su psichikos sveikata ir pasitenkinimu darbu. Pavyzdžiui, atliktoje apklausoje paaiškejjo, kad medicinos darbuotojams JAV yra svarbu daugiau praleisti laiko su pacientais ir medikai norètų daugiau dėmesio skirti pacientų gydymui (Onieal, 2008). Taip pat JAV darbuotojams yra ypač svarbi galimybè turèti lanksčias darbo valandas (Scandura \& Lankau, 1997).

Tyrimo rezultatai parode, kad medikų empatijos, psichikos sveikatos ir pasitenkinimo darbu lygis Lietuvoje ir JAV nesiskiria. Šiuos rezultatus interpretuoti galima dèmesị atkreipiant ị Lietuvai ir JAV būdingus panašumus. Abi šalys yra priskiriamos prie individualistinių kultūrų (Kononovas \& Dallas, 2009). İdomu tai, kad individualistinės šalys pasižymi panašiais rodikliais: geresne psichikos sveikata bei didesniu pasitenkinimu darbu nei kolektyvistinès šalys (McCormik \& Cooper, 1988; cit. pagal Spector et al., 2001).

Siekiant išsiaiškinti empatijos ir psichikos sveikatos svarbą prognozuojant pasitenkinimą darbu buvo nustatyta, kad Lietuvos medicinos darbuotojų imtyje abu šie veiksniai nèra svarbūs prognozuojant pasitenkinimą darbu. Anksčiau Lietuvos medikų imtyje atlikti tyrimai parodè, kad jų pasitenkinimas darbu yra susijęs su autonomijos jausmu, o nepasitenkinimą darbu iššaukia tokie veiksniai kaip socialinis statusas, darbo krūvis bei kompensacijos (Bučiūnienè, Blazevičienè, \& Bliudžiūtè, 2005). Kitas svarbus veiksnys - darbo laikas: kokiu paros metu ir kiek laiko medikas dirba (Kaur, Sharma, Talwar, Verma, \& Singh, 2009). Šie ir kiti faktoriai gali būti itin svarbūs prognozuojant pasitenkinimo darbu lygi Lietuvos medikų imtyje.

Kadangi dar šiame tyrime buvo nustatyta, kad egzistuoja šių trijų reiškinių sąsajos, tačiau ne psichikos sveikata ir empatija lemia medicinos darbuotojo pasitenkinimą darbu, todèl gali būti, kad patenkintas darbu medikas yra labiau empatiškas ir geresnès psichikos sveikatos. Tai patvirtina seniau gautus rezultatus - pasitenkinimas darbu yra vienas svarbiausių faktorių sveikatos priežiūros personalui, kuris užtikrina gerą paciento priežiūros kokybę (Clark et al., 2007; Korzeniewska-Eksterowicz et al., 2010) bei asmeninę medico gerovę (Sharma et. al., 2014). 
Analizuojant medicinos darbuotojų JAV pasitenkinimo darbu prognozę remiantis empatija ir psichikos sveikata buvo aptiktas reikšmingas psichikos sveikatos poveikis pasitenkinimui darbu. Šie rezultatai paremia anksčiau atliktą tyrimą JAV, kurio metu buvo nustatyta, kad psichikos sveikata yra ypač svarbi pasitenkinimui darbu (Kleiner \& Pavalko, 2010). Matoma, kad psichikos sveikata prognozuoja pasitenkinimą darbu JAV medikų imtyje, o Lietuvos medicinos darbuotojų imtyje tokios tendencijos neatsispindejo. Tokiems rezultatams atsirasti poveiki galèjo padaryti tai, kad pastaruoju metu JAV buvo itin susirūpinta gyventojų psichikos sveikata, kadangi buvo pastebėtas ženklus jos suprastejimas (U.S. Department of Health and Human Services, 2013). Tai gali reikšti, jog psichikos sveikatos reikšmė JAV gyventojams padidejjusi, todèl ji daro didesnị nei kiti veiksniai poveikị tiek pasitenkinimui darbu, tiek galbūt ir pasitenkinimui gyvenimu.

Apibendrinant galima teigti, kad Lietuvos medicinos darbuotojų pasitenkinimas darbu, empatija ir psichikos sveikata yra charakteristikos, ị kurias reikia atkreipti dėmesị. JAV medikams empatija nèra reikšminga lyginant su kitomis dviejomis charakteristikomis, nors šių trijų reiškinių lygis reikšmingai nesiskiria Lietuvos ir JAV medikų imtyse.

\title{
Išvados
}

Lietuvos medicinos darbuotojų pasitenkinimas darbu, empatija ir psichikos sveikata yra teigiamai susiję. Pasitenkinimas darbu ir psichikos sveikata yra teigiamai susiję, o empatija nesusijusi su psichikos sveikata ir pasitenkinimu darbu tarp JAV medicinos darbuotojų. Visų šių trijų reiškinių lygis tarp medicinos darbuotojų Lietuvoje ir JAV nesiskiria. Prognozuojant pasitenkinimą darbu tarp medicinos darbuotojų Lietuvoje nei pasitenkinimas darbu, nei empatija nèra svarbūs veiksniai, JAV medikų psichikos sveikata yra svarbus veiksnys prognozuojant pasitenkinimą darbu, o empatija nėra svarbus veiksnys.

\section{Padèka}

Dėkojame letk. Ingai Truskauskaitei - Kunevičienei už vertingas pastabas rengiant straipsnị.

\section{The Relationship Between Job Satisfaction, Empathy and Mental Health Among Medical Staff In Lithuania and The USA}

\author{
Dovile MILISAUSKAITE ${ }^{1}$ \\ Mykolas Romeris University \\ ${ }^{1}$ Corresponding author: dovile.milisauskaite@gmail.com
}

\begin{abstract}
The aim of this paper was to analyse the relationship between empathy, mental health and job satisfaction among medical workers in Lithuania and the USA. 100 private sector medical workers from Lithuania and the USA participated in the research. The questionnaires were used for the quantitative evaluation: empathy was measured by Jefferson Empathy Scale HP-Version, mental health was measured by Mental Health Inventory, and job satisfaction - by Job Satisfaction Survey. The results have shown the relationship between empathy, mental health, and job satisfaction in Lithuanian sample and the relationship between mental health and job satisfaction among medical workers in the USA. There was no significant difference in the levels of empathy, mental health, and job satisfaction among the medical staff in Lithuania and the USA. It was also found that neither empathy, nor mental health was a significant factor while predicting job satisfaction in the sample of Lithuanian medical workers, but mental health was a significant predictor of job satisfaction among the medical staff in the USA.

Keywords. Empathy, mental health, job satisfaction, cross-cultural, health care
\end{abstract}




\section{Literatūra}

Altaf, A., \& Awan, M. A. (2011). Moderating Affect of Workplace Spirituality on the Ralationship of Job Overload and Job Satisfaction. Journal of business ethics, 104(1), 93-99.

Arnold, L. (2002). Assessing Professional Behavior: Yesterday, Today and Tomorrow. Academic Medicine, 77, $502-515$.

Bockerman, P., \& Ilmakunnas, P. (2012). The job satisfaction-productivity nexus: A study using matched survey and register data. Industrial \& Labor Relations Review, 65(2), 244-262.

Bučiūnienè, I., Blazevičienè, A., \& Bliudžiūtè, E. (2005). Health care reform and job satisfaction of primary health care physicians in Lithuania. BMC Family Practice, 6(1), 10.

Burks, D. J., \& Kobus, A. M. (2012). The legacy of altruism in health care: the promotion of empathy, prosociality and humanism. Medical Education, 46(3), 317-325.

Clark, L., Leedy, S., McDonald, L., Muller, B., Lamb, Ch., Mendez, T., Kim, S., \& Schonwetter, R. (2007). Spirituality and Job Satisfaction among Hospice Interdisciplinary Team Members. Journal of Palliative Medicine, 10(6), 1321-1328. doi: 10.1089/jpm.2007.0035.

Cottini, E., \& Lucifora, C. (2013). Mental Health and Working Conditions In Europe. Industrial \& Labor Relations Review, 66(4), 958-988.

Di Blasi, Z. , Harkness, E., Ernst, E., Georgiou, A., \& Kleijnen, J. (2001). Influence of context effects on health outcomes: a systematic review. The Lancet, 357(9258), 757-762.

Dubnicki, C. (1977). Relationships Among Therapist Empathy and Authoritarianism and a Therapist's Prognosis. Journal of Consulting and Clinical Psychology, 45(5), 958-959.

Fiabane, E., Giorgi, I., Sguazzin, C., \& Argentero, P. (2013). Work engagement and occupational stress in nurses and other healthcare workers: the role of organisational and personal factors. Journal of Clinical Nursing, 22(17-18), 2614-2624.

Hojat, M., \& Mangione, S. (2001). Jefferson Scale of Physician Empathy. Health Policy Newsletter, 14(4).

Hojat M., Mangione S., Kane G. C., Gonnella J. S. (2005). Relationships between scores of the Jefferson Scale of Physician Empathy (JSPE) and the Interpersonal Reactivity Index (IRI). Medical Teacher, 27(7), 625-628.

Kaur, S., Sharma, R., Talwar, R., Verma, A., \& Singh, S. (2009). A study of job satisfaction and work environment perception among doctors in a tertiary hospital in Dehli. Indian Journal of Medical Sciences, 63(4), 139-144.

Kleiner, S., \& Pavalko, E. K. (2010). Clocking In: The Organization of Work Time and Health in the United States. Social Forces, 88(3), 14631486

Kononovas, K., \& Dallas, Th. (2009). A cross-cultural comparison of perceived stress and self-efficacy across Japanese, U.S. and Lithuanian students. PSICHOLOGIJA, 39, 59-70.

Korzeniewska-Eksterowicz, A., Przyslo, L., Grzelewski, T., Stolarska, M., Mlynarski, W., Stelmach, I., Krakowiak, J., \& Stalmach, W. (2010). Job satisfaction among health professionals of Home Hospice for Children of Lodz Region. Advances in Palliative Medicine, 9(3), 67-72.

Larson E. B., Yao X. (2005). Clinical Empathy as Emotional Labor in the Patient-Physician Relationship. JAMA, 293(9), 1100-1106. doi:10.1001/jama.293.9.1100.

Lauder, W., Kroll, T., \& Jones, M. (2007). Social determinants of mental health: the missing dimensions of mental health nursing? Journal of Psychiatric and Mental Health Nursing, 14(7), 661-669.

Mercer, S. W., \& Reynolds W. J. (2002). Empathy and quality of care. British Journal of General Practice, 52, S9-12.

Onieal, M. - E. (2008). It's Roll-Up-Your-Sleeves Time. Clinician Reviews, 18(12), CR-33.

Paro, H. B. M. S., Silveira, P. S. P., Perotta, B., Gannam, S., Enns, S. C., Giaxa, R. R. B., Bonito, R. F., Martins, M. A., \& Tempski, P. Z. (2014). Empathy among Medical Students: Is There a Relation with Quality of Life and Burnout? PloS one, 9(4), 1-10.

Perry B. D. (2003). The cost of caring: Secondary traumatic stress and the impact of working with high-risk children and families. The Child Trauma Academy.

Radley, M., \& Figley, C. R. (2007). The Social Psychology of Compassion. Clinical Social Work Journal, 35(3), $207-214$.

Rogers, C. R. (1957). The necessary and sufficient conditions of therapeutic personality change. Journal of Consulting and Clinical Psychology, 21(2), 95-103.

Scandura, T. A., \& Lankau, M. J. (1997). Relationships of gender, family responsibility and flexible work hours to organizational commitment and job satisfaction. Journal of organizational Behavior, 18(4), 377-391.

Sharma M., Goel S., Singh Sh. K., Sharma R., Gupta P. K. (2014). Determinants of Indian physicians' satisfaction \& dissatisfaction from their job. The Indian journal of medical research, 139(3), 409-417.

Spector, P. E. (1985). Measurement of Human Service Staff Satisfaction: Development of the Job Satisfaction Survey. American Journal of Community Psychology, 13(6), 693-713.

Spector, P. E., Cooper, C. L., Sanchez, J. I., O’Driscoll, M., Sparks, K., Bernin, P., Bussing, A., Dewe, P., Hart, P., Lu, L., Miller, K., De Moraes, L. F. R., Ostrognay, G. M., Pagon, M., Pitariu, H., Poelmans, S., Radhakrishnan, P., Russinova, V., Salamatov, V., Salgado, J., Shima, S., Siu, O. L., Stora, J. B., Teichmann, M., Theorell, T., Vlerick, P., Westman, M., Widerszal-Bazyl, M., Wong, P., \& Yu, S. (2001). Do national levels of individualism and internal locus of control relate to well-being: an ecological level international study. Journal of Organizational Behavior, 22(8), 815-832.

Suzuki, K., Ohida, T., Kaneita, Y., Yokoyama, E., Miyake, T., Harano, S., Yagi, Y., Ibuka, E., Kaneko, A., Tsutsui, T., \& Uchiyama, M. (2004). Mental Health Status, Shift Work, and Occupational Accidents among Hospital Nurses in Japan. Journal of Occupational Health, 46(6), 448454.

Thommasen, H. V., Lavanchy, M., Connelly, I., Berkowitz, J., \& Grzybowski, S. (2001). Mental health, job satisfaction and intention to relocate. Opinions of physicians in rural British Columbia. Canadian Family Physician, 47(4), 737-744.

U.S. Department of Health and Human Services. (2013). Results from the 2012 National Survey on Drug Use and Health: Mental Health Findings. Prieiga per interneta http://archive.samhsa.gov/data/NSDUH/2k12MH_FindingsandDetTables/2K12MHF/NSDUHmhfr2012.htm\#ch1. Williams, E. S., Konrad, R. Th., Scheckler, W. E., Pathman, D. E., Linzer, M., McMurray, J., Gerrity, M., \& Schwartz, M. (2000). The effects of job satisfaction and perceived stress on the physicial and mental health and withdraw intentions of physicians. Academy of Management Proceedings, 2000(1), C1-C6.

World Health Organization, Global Atlas of the Health Workforce. (2014). Prieiga per internetą http://data.worldbank.org/indicator/SH.MED.PHYS.ZS 